\title{
Antinociceptive Interactions between Mu-Opioid Receptor Agonists and the Serotonin Uptake Inhibitor Clomipramine in Rhesus Monkeys: Role of Mu Agonist Efficacy
}

\author{
Matthew L. Banks, Kenner C. Rice, and S. Stevens Negus \\ Department of Pharmacology and Toxicology, Virginia Commonwealth University, Richmond, Virginia (M.L.B., S.S.N.); and \\ Chemical Biology Research Branch, National Institute on Drug Abuse and National Institute on Alcohol Abuse and Alcoholism, \\ National Institutes of Health, Bethesda, Maryland (K.C.R.)
}

Received April 14, 2010; accepted July 29, 2010

\begin{abstract}
Mu-opioid agonists are effective analgesics but have undesirable effects such as sedation and abuse liability that limit their clinical effectiveness. Serotonergic systems also modulate nociception, and serotonin uptake inhibitors may be useful as adjuncts to enhance analgesic effects and/or attenuate undesirable effects of mu agonists. This study examined the effects of the serotonin uptake inhibitor clomipramine on behavioral effects produced in rhesus monkeys by mu agonists with varying efficacy at mu receptors (nalbuphine $<$ morphine $<$ methadone). Clomipramine and each mu agonist were studied alone and in fixed-proportion mixtures in assays of schedule-controlled responding, thermal nociception, and capsaicin-induced thermal allodynia. In the assay of schedule-controlled responding, all mu agonists dose-dependently decreased response rates. Clomipramine was inactive alone and did not alter the effects of mu agonists. In the assay of thermal nociception, all mu agonists
\end{abstract}

produced dose-dependent antinociception. Clomipramine was inactive alone but produced a proportion-dependent enhancement of the antinociceptive effects of nalbuphine $>$ morphine $>$ methadone. In the assay of capsaicin-induced allodynia, nalbuphine produced dose-dependent antiallodynia. Clomipramine alone was inactive, but as in the assay of thermal nociception, it produced a proportion-dependent enhancement in the effects of nalbuphine. These findings suggest that serotonin uptake inhibitors can selectively enhance the antinociceptive effects of mu agonists in nonhuman primates. These effects of serotonin uptake inhibitors may depend on the proportion of the serotonin uptake inhibitor and the efficacy of the mu agonist. The greatest enhancement was observed with intermediate proportions of clomipramine in combination with the low-efficacy mu agonist nalbuphine.

\section{Introduction}

Mu-opioid agonists are commonly used in the treatment of pain. Although mu agonists are effective analgesics, they also have undesirable effects such as sedation and abuse liability that limit their clinical utility. In the development of analgesics with improved therapeutic profiles, one strategy has been to combine mu agonists with other compounds targeting other biological receptor systems to selectively enhance the antinociceptive effects and/or attenuate undesirable effects

This research was supported by the National Institutes of Health National Institute on Drug Abuse [Grants R01-DA011460, T32-DA007027]; the Intramural Research Programs of the National Institute on Drug Abuse; and the National Institute on Alcohol Abuse and Alcoholism.

Article, publication date, and citation information can be found at http://jpet.aspetjournals.org.

doi:10.1124/jpet.110.169276.
(Dietis et al., 2009). Toward this end, the serotonin system might be one possible biological target of interest.

Nociception is modulated by multisynaptic descending pathways that include both opioidergic and serotonergic mechanisms (Basbaum and Fields, 1984). Opioids can act directly at the spinal dorsal horn to block nociceptive transmission by primary afferent nociceptors or indirectly at supraspinal levels to inhibit GABAergic inputs and thereby modulate rostroventral medulla off and on cells and produce a net descending inhibition of nociceptive transmission (Fields et al., 2006). Serotonergic descending neurons also originating in the rostroventral medulla tonically release serotonin in the spinal dorsal horn and may influence nociceptive input by amplifying the impact of other descending inhibitory systems (Fields et al., 2006). Moreover, there seems to be a descending serotonergic facilitatory nociceptive pathway originating in the brainstem and targeting $5-\mathrm{HT}_{3}$

ABBREVIATIONS: \%MPE, percentage maximum possible effect; DR, dose ratio; ANOVA, analysis of variance; SCR, schedule-controlled responding; SNC80, $(+)-4-[(\alpha R)-\alpha-((2 S, 5 R)-4$-allyl-2,5-dimethyl-1-piperazinyl)-3-methoxybenzyl]-N,N-diethylbenzamide; U-69593, $N$-methyl-2phenyl- $N$-[(5R,7S,8S)-7-(pyrrolidin-1-yl)-1-oxaspiro[4.5]dec-8-yl]acetamide. 
receptors in the dorsal horn (Suzuki et al., 2002; Rahman et al., 2004; Bannister et al., 2009). Overall, these results suggest that serotonin may play a role in the detection of noxious stimuli and pharmacological modulation of this serotonergic system might be a biological target of therapeutic value.

In agreement with this possibility, previous studies have shown that drugs inhibiting serotonin uptake may enhance the antinociceptive effects of mu agonists. For example, we reported that pretreatment with a single fixed dose of the serotonin uptake inhibitor clomipramine $(0.1 \mathrm{mg} / \mathrm{kg})$ enhanced the antinociceptive effects of mu agonists in nonhuman primates. The effects of clomipramine depended on the efficacy of the mu agonist, with greater enhancement of low-efficacy agonists (Gatch et al., 1998). Moreover, this enhanced antinociceptive effect was replicated with the selective serotonin uptake inhibitor fluoxetine, but not with dopamine or norepinephrine transporter inhibitors, suggesting that the effect depended on serotonin transporter inhibition (Gatch et al., 1998). Clomipramine has also been shown to enhance the antinociceptive effects of morphine in rodents (Kellstein et al., 1984; Ansuategui et al., 1989; Sierralta et al., 1995). Overall, these studies suggest further research on mu agonist and serotonin uptake inhibitor drug mixtures as candidate analgesics is warranted.

The aim of the present study was to confirm our previous finding of clomipramine enhancement of mu agonist antinociception and extend these findings in three ways. First, our previous study examined the effects of a single clomipramine dose administered as a pretreatment to multiple mu agonist doses. However, drug interactions can also be profitably studied by using fixed-proportions drug mixtures (Tallarida, 2000; Stevenson et al., 2003; Negus et al., 2008, 2009), and clinically available drug-combination products typically exist as fixed-proportion mixtures. Therefore, the present study examined effects of clomipramine administered in fixed proportions with the low-efficacy mu agonist nalbuphine, the moderate-efficacy mu agonist morphine, and the high-efficacy mu agonist methadone. Second, the selectivity of clomipramine-mu agonist interactions for antinociception versus other effects is unknown. Insofar as motor impairment and nonspecific behavioral suppression may confound measures of thermal nociception, we therefore determined clomipramine-mu agonist interactions in an assay of schedule-controlled responding for comparison with antinociceptive interactions (Stevenson et al., 2003; Negus et al., 2008, 2009). Finally, to assess the generality of antinociceptive interactions to a model of inflammatory pain, clomipramine-nalbuphine interactions were also examined in an assay of capsaicin-induced thermal allodynia (Negus et al., 1993; Butelman et al., 2004; Do Carmo et al., 2008). We hypothesized that clomipramine would selectively enhance the antinociceptive and antiallodynic effects of mu agonists. Confirmation of our hypothesis would support further development of mu-opioid agonist and serotonin uptake inhibitor mixtures as candidate analgesics.

\section{Materials and Methods}

\section{Subjects}

Ten monkeys served as subjects. Three adult male rhesus monkeys (Macaca mulatta) were used in studies of schedule-controlled responding, four monkeys (two female and two male) were used in studies of thermal nociception, and three male monkeys were used in studies of capsaicin-induced thermal allodynia. Subjects weighed 4.5 to $12 \mathrm{~kg}$ during the course of these studies, and all monkeys had prior exposure to drugs (primarily dopaminergic and opioid compounds) and the behavioral procedures in which they were tested. The subjects were individually housed, and water was freely available. Their diet consisted of Lab Diet monkey chow (Purina, St. Louis, MO). This diet was supplemented with fresh fruit twice daily. In addition, monkeys in the assay of schedule-controlled behavior could earn additional food pellets during experimental sessions. A 12-h light/ 12-h dark cycle was in effect (lights on from 7:00 AM to 7:00 PM).

Animal maintenance and research were conducted in accordance with the guidelines provided by the National Institutes of Health Committee on Laboratory Animal Resources. The facility was licensed by the United States Department of Agriculture and the Association for Assessment and Accreditation of Laboratory Animal Care, and protocols were approved by the Institutional Animal Care and Use Committee. The health of the monkeys was monitored daily by technical staff and periodically by a veterinarian. Monkeys had visual, auditory, and olfactory contact with other monkeys throughout the study. Monkeys also had access to puzzle feeders, mirrors, and chew toys to provide environmental enrichment. Music or movies were played daily in the housing room.

\section{Behavioral Procedures}

Assay of Schedule-Controlled Responding. Experiments were conducted in each monkey's home cage (dimensions $60 \times 65 \times 75 \mathrm{~cm}$ ) as described previously (Stevenson et al., 2003; Negus et al., 2008, 2009). Each cage was modified to include an operant response panel $(28 \times 28 \mathrm{~cm})$ mounted on the front wall. Three square translucent response keys $(5.1 \mathrm{~cm}$ in diameter) were arranged $2.5 \mathrm{~cm}$ apart in a horizontal row $3.2 \mathrm{~cm}$ from the top of the operant panel. Each key could be transilluminated by red, green, or yellow stimulus lights. The operant panel also supported an externally mounted pellet dispenser (MED Associates, St. Albans, VT) that delivered 1-g bananaflavored food pellets (Test Diets, Richmond, IL) to a food receptacle mounted on the cage beneath the operant response panel. The panel was controlled by a MED-PC interface and an IBM-compatible computer programmed in MEDSTATE Notation (MED Associates).

Experimental sessions were $75 \mathrm{~min}$ in duration and consisted of five 15-min cycles. Each cycle consisted of two components: a 10-min timeout period followed by a 5 -min response period. During the timeout period, no stimulus lights were illuminated, and responding had no scheduled consequences. During the response period, the center key was transilluminated yellow, and the subjects could respond for up to 10 food pellets under a fixed-ratio 30 schedule of reinforcement. If all 10 food pellets were earned before $5 \mathrm{~min}$ had elapsed, the lights were turned off, and responding had no scheduled consequences for the remainder of that response period. All monkeys were trained until they responded at rates more than 1.0 response/s during all five cycles for 10 consecutive days, and we have shown previously that monkeys respond at relatively stable rates across successive response periods in this procedure (Stevenson et al., 2003; Negus et al., 2008, 2009).

Sessions were conducted 5 days a week. Test sessions usually were conducted on Tuesdays and Fridays, and training sessions were conducted on Mondays, Wednesdays, and Thursdays. In addition, test sessions were conducted only after a training session during which the monkeys responded at rates more than 1.0 response/s for all five cycles. During training sessions, monkeys received either no injection or saline injections at the beginning of each cycle. During test sessions, test compounds were administered by using a cumulative dosing procedure, in which doses of the test drug or drug mixture were administered at the beginning of each cycle, and each dose increased the total cumulative dose by one-fourth or one-half log units.

Initially, dose-effect curves were determined for nalbuphine (0.032-3.2 mg/kg), morphine (0.032-3.2 mg/kg), methadone (0.1-5.6 
$\mathrm{mg} / \mathrm{kg})$, and clomipramine $(0.1-10 \mathrm{mg} / \mathrm{kg})$ alone, and each drug was tested twice. $\mathrm{Mu}$ agonists were tested up to doses that eliminated responding. Higher clomipramine doses were not tested to minimize risk of potential untoward effects such as convulsions (Pisani et al., 2002). Subsequently, three mixtures of clomipramine in combination with each mu agonist were examined. Because clomipramine was inactive in this or the other procedures used in this study the relative potency of clomipramine to the mu agonists could not be used to adjust clomipramine dose in accordance with procedures for doseaddition analysis (e.g., Stevenson et al., 2003; Negus et al., 2008, 2009). Consequently, the clomipramine proportions were initially calibrated to methadone, the least potent of the mu agonists studied. Thus, clomipramine/methadone mixtures were studied across a range of three proportions $(0.33: 1,1: 1$, and 3:1 clomipramine/methadone) such that the intermediate proportion was 1:1 clomipramine/ methadone, and 3-fold lower and higher proportions were also studied. Proportions of clomipramine with the other mu agonists were then adjusted according to the relative potency of those drugs in comparison to methadone. Thus, morphine was 1.6 -fold more potent than methadone, and clomipramine proportions were increased by a factor of $1.6(0.53: 1,1.6: 1$, and 4.8:1 clomipramine/morphine). Likewise, nalbuphine was 5.2-fold more potent than methadone, and clomipramine proportions were increased by a factor of $5.2(1.7: 1$, $5.2: 1$, and 15.6:1). In this way, a constant relationship was maintained between the proportion of clomipramine and the relative potency of the mu agonist in the assay of schedule-controlled responding. Each mixture was tested once, and 1 week separated each test. Nalbuphine, morphine, methadone, and all mixtures were tested up to doses that eliminated responding in most or all monkeys.

Assay of Thermal Nociception. Monkeys were seated in acrylic restraint chairs so that their tails hung down freely. The bottom 10 $\mathrm{cm}$ of each monkey's shaved tail was immersed in a thermal container of warm water. If the subject did not remove its tail within $20 \mathrm{~s}$, the experimenter removed the tail, and a latency of $20 \mathrm{~s}$ was assigned to that measurement. During each cycle of measurements, tail-withdrawal latencies were measured from water heated to 38 , 50 , and $54^{\circ} \mathrm{C}$. The order in which the temperatures were presented varied from one set of measurements to the next. Experiments were conducted no more than twice a week. A stopwatch was used to measure and record time intervals.

Each test session consisted of multiple 15-min cycles. Before the first drug dose was administered, baseline latencies to tail withdrawal at 38,50 , and $54^{\circ} \mathrm{C}$ water were determined. Testing continued only if tail withdrawal from $38^{\circ} \mathrm{C}$ water did not occur before the 20 -s cutoff, and if tail withdrawal occurred in $\leq 2 \mathrm{~s}$ from 50 and $54^{\circ} \mathrm{C}$ water. This criterion was met during every session with every monkey in this study. During cumulative dosing experiments, a single drug dose was administered at the start of each of five sequential 15-min cycles, and each dose increased the total cumulative dose by one-fourth or one-half log units. Starting 10 min after each injection, tail-withdrawal latencies were recorded as described above. Initially, complete dose-effect curves were determined for nalbuphine $(0.32-$ $3.2 \mathrm{mg} / \mathrm{kg}$, one monkey tested with $10 \mathrm{mg} / \mathrm{kg}$ ), morphine $(0.1-5.6$ $\mathrm{mg} / \mathrm{kg})$, methadone $(0.1-5.6 \mathrm{mg} / \mathrm{kg})$, and clomipramine $(0.1-5.6 \mathrm{mg} /$ $\mathrm{kg}$ ) alone. $\mathrm{Mu}$ agonists were tested up to doses producing maximal antinociception by using the $50^{\circ} \mathrm{C}$ thermal stimulus, and clomipramine doses were limited as discussed above. Subsequently, three mixtures of each mu agonist in combination with clomipramine were examined, and the proportions of each drug in the mixtures were identical to those examined in the assay of schedule-controlled responding described above. Each drug mixture was tested once.

The time courses of saline and selected doses of nalbuphine (1.0 $\mathrm{mg} / \mathrm{kg})$, morphine $(3.2 \mathrm{mg} / \mathrm{kg})$, methadone $(3.2 \mathrm{mg} / \mathrm{kg})$, and clomipramine $(10 \mathrm{~m} / \mathrm{kg})$ were also examined in the assay of thermal nociception by using a stimulus intensity of $50^{\circ} \mathrm{C}$. For these studies, baseline tail withdrawal latencies from $50^{\circ} \mathrm{C}$ water were determined before drug treatment and $3,10,17,30,56,100$, and 300 min after drug treatment.
Assay of Capsaicin-Induced Thermal Allodynia. Monkeys were seated in acrylic restraint chairs as described above. The base of each monkey's tail was shaved, and baseline tail-withdrawal latencies were measured from water heated to $38,42,46$, and $50^{\circ} \mathrm{C}$. Temperatures were presented in random order. If the subject did not withdraw its tail within $20 \mathrm{~s}$, the experimenter removed the tail, and a latency of $20 \mathrm{~s}$ was assigned for that measurement. Using this procedure, temperature-effect curves were determined in each monkey at the beginning of each session, and the highest temperature that failed to elicit tail withdrawal was determined (i.e., the highest temperature to produce a tail-withdrawal latency of $20 \mathrm{~s}$ ). Water heated to this temperature then served as the thermal stimulus for subsequent studies of allodynia during that session. Allodynia was elicited by topical application of capsaicin as described previously (Butelman et al., 2004; Do Carmo et al., 2008). After baseline tailwithdrawal latency determinations, the tail of each subject was degreased with an alcohol pad. A topical capsaicin patch was prepared as described below (see Drugs), and the patch was applied to a region $\sim 5 \mathrm{~cm}$ from the bottom of the tail for $5 \mathrm{~min}$. After $5 \mathrm{~min}$, the patch was removed and tail-withdrawal latencies were redetermined by using the thermal stimulus identified from the baseline temperature-effect curve. Initially, nalbuphine $(0.032-1.0 \mathrm{mg} / \mathrm{kg})$ and clomipramine $(1.0-10 \mathrm{mg} / \mathrm{k} / \mathrm{g})$ were tested alone. Subsequently, three mixtures of nalbuphine in combination with clomipramine were examined, and the proportions of each drug in the mixtures were identical to those examined in the assay of schedule-controlled responding described above. Tests were conducted no more than twice per week.

\section{Data Analysis}

For the assay of schedule-controlled responding, raw response rates from each test cycle were converted to percentage of control by using the average rate from the previous training day in that monkey as the control value. For the assay of thermal nociception, raw tail withdrawal latencies were expressed as percentage maximum possible effect (\% MPE) by using the equation $\% \mathrm{MPE}=[$ (test latency - baseline latency $) /(20-$ baseline latency $)] \times 100$, where test latency was the tail-withdrawal latency obtained after drug administration, baseline latency was the latency obtained at that temperature at the beginning of the session before drug administration, and 20 was the cutoff latency in seconds. For the assay of capsaicininduced thermal allodynia, raw tail-withdrawal latencies obtained $15,30,45$, and $60 \mathrm{~min}$ after removal of the capsaicin patch were converted to \%MPE by using the equation \%MPE = [(test latency capsaicin alone latency $) /(20$ - capsaicin alone latency) $] \times 100$, where test latency was the tail-withdrawal latency obtained at each time point after drug pretreatment + capsaicin patch treatment, capsaicin alone latency was the latency obtained at the corresponding time point after treatment with the capsaicin patch alone, and 20 was the cutoff latency in seconds. Data from all four time points after capsaicin patch removal were then averaged to yield a mean \pm S.E.M. \%MPE for each monkey during each session.

Data for each mu agonist alone and in combination with different proportions of clomipramine were analyzed by using a two-way repeated-measures analysis of variance (ANOVA) with mu agonist dose and clomipramine proportion as the main factors. In the presence of a significant main effect, post hoc analysis was conducted by using the Bonferroni $t$ test method for planned comparisons between each drug mixture and the $\mathrm{mu}$ agonist alone. In addition, $\mathrm{ED}_{50}$ values were determined for each mu agonist alone and in combination with clomipramine in each monkey. $\mathrm{ED}_{50}$ values were calculated by interpolation when only two data points were available (one below and one above 50\% effect) or linear regression when at least three data points were available on the linear portion of the dose-effect curve. Individual $\mathrm{ED}_{50}$ values were averaged to yield mean $\mathrm{ED}_{50} \mathrm{~S}$ and $95 \%$ confidence limits. Significance was established a priori at the $95 \%$ confidence level.

To evaluate drug interactions across assays, the relative potency 

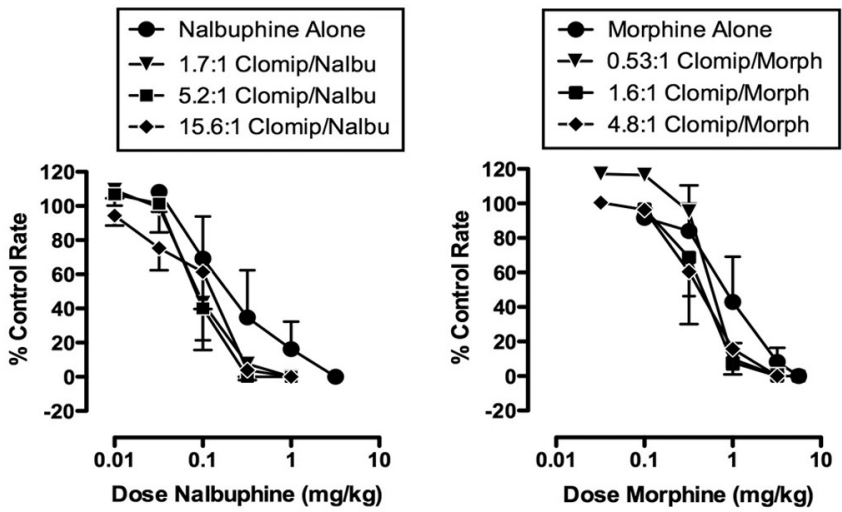

of each mu agonist and drug mixture to produce rate suppression versus antinociception was quantified by using dose ratio (DR) analysis as described previously (Negus et al., 2008, 2009; Banks et al., 2010). Specifically, DRs for each mu agonist or drug mixture were calculated as the ratio of the $\mathrm{ED}_{50}$ in the assay of schedule-controlled responding/ $/ \mathrm{ED}_{50}$ in the assay of thermal nociception $\left(50\right.$ and $54^{\circ} \mathrm{C}$ ). Thus, if a drug or drug mixture was equipotent in the two procedures, then $\mathrm{ED}_{50}$ in the assay of schedule-controlled responding would be equal to the $\mathrm{ED}_{50}$ in the assay of thermal nociception, and $\mathrm{DR}=1$. A DR $>1$ indicates that the drug or drug mixture was more potent in the assay of thermal nociception. Conversely, DR $<1$ indicates that the drug or drug mixture was more potent in the assay of schedule-controlled responding. For nalbuphine administered alone or in combination with clomipramine, DRs were also calculated for rate suppression versus antiallodynia as $\mathrm{ED}_{50}$ in the assay of schedule-controlled responding/ $\mathrm{ED}_{50}$ in an assay of capsaicin-induced thermal allodynia. The potency of each drug or drug mixture was considered to be different across procedures if the $95 \%$ confidence limits of the $\mathrm{ED}_{50}$ values in the procedures did not overlap.

Time course data in the assay of thermal nociception were analyzed by two-way repeated-measures ANOVA, with drug (saline, clomipramine, nalbuphine morphine, and methadone) as one factor and time after administration (3, 10, 17, 30, 56, 100, and $300 \mathrm{~min})$ as the second factor. A significant ANOVA was followed by the Bonferroni post hoc test for multiple planned comparisons. The criterion for significance was set a priori at the $95 \%$ confidence level.

\section{Drugs}

Racemic methadone $\mathrm{HCl}$ and (-)-morphine sulfate were provided by the National Institute on Drug Abuse (Bethesda, MD). Nalbu-

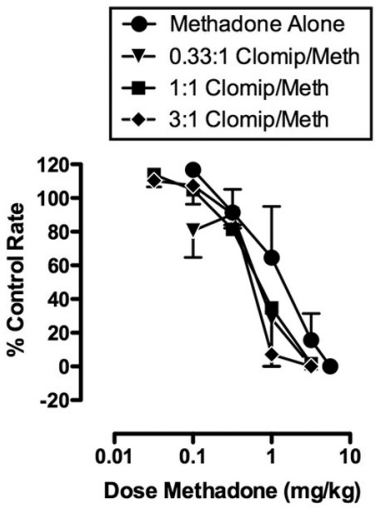

Fig. 1. Effects of nalbuphine (Nalbu; left), morphine (Morph; center), and methadone (Meth; right) alone or in combination with different proportions of clomipramine (Clomip) in the assay of schedule-controlled responding. Abscissae: dose of mu agonist alone or in the mixture in $\mathrm{mg} / \mathrm{kg}$ (log scale). The corresponding dose of clomipramine depended on the proportion of clomipramine in the mixture. Ordinates: percentage control rates of responding. Each point shows mean \pm S.E.M. for three monkeys.

phine $\mathrm{HCl}$ was generously provided by Dr. Kenner Rice (Chemical Biology Research Branch, National Institute on Drug Abuse and National Institute on Alcohol Abuse and Alcoholism, Bethesda, MD). Clomipramine $\mathrm{HCl}$ was obtained from Sigma-Aldrich (St. Louis, MO). Mu agonists and clomipramine were dissolved in sterile water for intramuscular injection in the thigh, and doses are expressed in terms of the salt forms listed above. Capsaicin (Sigma-Aldrich) was dissolved in a vehicle composed of $70 \%$ alcohol and $30 \%$ sterile water approximately $15 \mathrm{~min}$ before use, and it was delivered transdermally (topical patch). Specifically, the patch consisted of a $1-\mathrm{cm}^{2}$ piece of two-ply gauze affixed to adhesive backing (23-mm wide; Nexcare bandages) and 12-cm long elastic tape (5-cm wide; Elastikon tape) purchased from Henry Schein, Inc. (Denver, PA). The $0.61 \mathrm{mg} / \mathrm{ml}$ capsaicin solution $(0.3 \mathrm{ml})$ was slowly injected onto the patch. Within $30 \mathrm{~s}$ of preparing the capsaicin patch, it was secured to the monkey's tail with the elastic tape and left on for $5 \mathrm{~min}$.

\section{Results}

Assay of Schedule-Controlled Responding. The average control response rate $( \pm$ S.E.M.) determined on the days preceding test days throughout the study was $2.9( \pm 0.1)$ responses/s. Figure 1 shows the dose-effect curves for nalbuphine (left), morphine (center), and methadone (right) administered alone. All of the mu agonists produced dose-dependent decreases in response rates, and the $\mathrm{ED}_{50}$ values are shown in Table 1. The serotonin uptake inhibitor clomipramine up to $10 \mathrm{mg} / \mathrm{kg}$ did not reliably alter response rates (data not shown), and an $\mathrm{ED}_{50}$ value could not be deter-

\section{TABLE 1}

$\mathrm{ED}_{50}$ values $95 \%$ confidence level) for each mu-opioid agonist administered alone or in combination with varying proportions of clomipramine in assays of schedule-controlled responding (SCR), thermal nociception at 50 and $54^{\circ} \mathrm{C}$, and capsaicin-induced thermal allodynia

\begin{tabular}{|c|c|c|c|c|}
\hline \multirow{2}{*}{ Treatment/Condition } & \multicolumn{4}{|c|}{$\mathrm{ED}_{50}(95 \%$ Confidence Level $)$} \\
\hline & $\mathrm{SCR}$ & $50^{\circ} \mathrm{C}$ & $54^{\circ} \mathrm{C}$ & Thermal Allodynia \\
\hline & \multicolumn{4}{|c|}{$m g / k g$} \\
\hline Nalbuphine alone & $0.23(0.06-0.91)$ & $0.89(0.23-3.40)$ & $>1.70^{b}(1.23-2.34)$ & $0.16(0.09-0.29)$ \\
\hline 1.7:1 Clomip/nalbuphine & $0.10(0.04-0.24)$ & $0.65(0.26-1.63)$ & $>1.43^{a}(0.53-3.87)$ & $0.13(0.12-0.13)$ \\
\hline 5.2:1 Clomip/nalbuphine & $0.10(0.08-0.12)$ & $0.16(0.05-0.52)$ & $0.84(0.46-1.52)$ & $0.06 *(0.05-0.07)$ \\
\hline 15.6:1 Clomip/nalbuphine & $0.09(0.04-0.22)$ & $0.23(0.07-0.76)$ & $1.21(0.53-2.77)$ & $0.09(0.05-0.17)$ \\
\hline Morphine alone & $0.74(0.24-2.27)$ & $2.46(1.53-3.97)$ & $>4.27^{a}(3.43-5.31)$ & \\
\hline 0.53:1 Clomip/morphine & $0.73(0.58-0.91)$ & $1.42(0.85-2.38)$ & $>3.81^{a}(3.29-4.40)$ & \\
\hline 1.6:1 Clomip/morphine & $0.54(0.40-0.75)$ & $1.31(0.56-3.06)$ & $3.39(2.66-4.31)$ & \\
\hline 4.8:1 Clomip/morphine & $0.59(0.40-0.86)$ & $2.16(1.21-3.88)$ & $3.59(2.51-5.13)$ & \\
\hline Methadone alone & $1.17(0.42-3.21)$ & $2.83(1.60-5.01)$ & $4.02(2.87-5.63)$ & \\
\hline 0.33:1 Clomip/methadone & $0.75(0.35-1.59)$ & $1.72(0.75-3.95)$ & $3.73(3.05-4.57)$ & \\
\hline 1:1 Clomip/methadone & $0.71(0.28-1.82)$ & $2.37(1.90-2.96)$ & $>4.69^{b}(3.80-5.79)$ & \\
\hline 3:1 Clomip/methadone & $0.56(0.37-0.85)$ & $3.73(3.08-4.52)$ & $>3.49^{b}(2.42-5.03)$ & \\
\hline
\end{tabular}

${ }^{a}$ Mean $\mathrm{ED}_{50}$ for three of four monkeys.

${ }^{b}$ Mean $\mathrm{ED}_{50}$ for two of four monkeys.

* Indicates that $95 \%$ confidence intervals do not overlap for nalbuphine in some proportion with clomipramine compared with nalbuphine alone. 
mined. Clomipramine maximally decreased rates of responding to $65.4 \pm 18.3 \%$ control (mean \pm S.E.M.) after $10 \mathrm{mg} / \mathrm{kg}$, and higher doses were not tested to minimize the risk of toxicity (Pisani et al., 2002).

Figure 1 also shows the dose-effect curves for nalbuphine (left), morphine (center), and methadone (right) administered in combination with different proportions of clomipramine. Clomipramine had little or no effect on the rate-decreasing effects of mu agonists. Two-way ANOVA indicated significant main effects for doses of each mu agonist [nalbuphine $\left(F_{3,6}=29.1\right)$, morphine $\left(F_{3,6}=23.2\right)$, methadone $\left(F_{3,6}=119.1\right) ; p<0.05$ ], but no significant main effect of clomipramine proportion and no significant interaction between mu agonist dose and clomipramine proportion. Table 1 shows that clomipramine did not significantly alter the $\mathrm{ED}_{50}$ value for any of the mu agonists to decrease rates of schedule-controlled responding.

Assay of Thermal Nociception. Under baseline conditions, monkeys never withdrew their tails from water heated to $38^{\circ} \mathrm{C}$. The mean \pm S.E.M. tail withdrawal latency from $50^{\circ} \mathrm{C}$ water was $0.9 \pm 0.1 \mathrm{~s}$ and from $54^{\circ} \mathrm{C}$ water it was $0.8 \pm$ 0.1 s. Figure 2 shows the dose-effect curves for each $\mathrm{mu}$ agonist administered alone at the two thermal intensities (50 and $54^{\circ} \mathrm{C}$ ), and $\mathrm{ED}_{50}$ values are shown in Table 1 . All three mu agonists produced dose-dependent antinociceptive effects at both stimulus intensities, but they differed in their potencies and maximal effects. Nalbuphine was the most potent compound. It increased \%MPE above $50 \%$ in all monkeys at $50^{\circ} \mathrm{C}$, but it increased \%MPE above $50 \%$ in only two of four monkeys at $54^{\circ} \mathrm{C}$. Morphine and methadone displayed similar potencies. Morphine increased \%MPE above $50 \%$ in all monkeys at $50^{\circ} \mathrm{C}$ but in only thee of four monkeys at $54^{\circ} \mathrm{C}$. Methadone increased \%MPE above $50 \%$ in all monkeys at both stimulus intensities. Clomipramine doses up to 5.6 $\mathrm{mg} / \mathrm{kg}$ did not produce a significant antinociceptive effect (data not shown), and $\mathrm{ED}_{50}$ values could not be calculated.
Clomipramine produced a maximum \%MPE of $10.0 \pm 5.7$ and $0.14 \pm 0.54$ after $5.6 \mathrm{mg} / \mathrm{kg}$ at 50 and $54^{\circ} \mathrm{C}$, respectively.

Figure 2 also shows the dose-effect curves for nalbuphine (left), morphine (center), and methadone (right) administered alone and in combination with different proportions of clomipramine at $50^{\circ} \mathrm{C}$ (top) and $54^{\circ} \mathrm{C}$ (bottom). In general, clomipramine enhanced the antinociceptive effects of mu agonists, and the most reliable enhancement was observed with the low-efficacy $\mathrm{mu}$ agonist nalbuphine. Two-way ANOVA for nalbuphine at the $50^{\circ} \mathrm{C}$ thermal intensity revealed significant main effects of nalbuphine dose $\left(F_{4,12}=\right.$ $36.3, p<0.05)$ and clomipramine proportion $\left(F_{3,9}=6.3, p<\right.$ 0.05 ), but no significant interaction. Post hoc analysis revealed that at nalbuphine doses of $0.1 \mathrm{mg} / \mathrm{kg}$ (5.2:1 mixture) and $0.32 \mathrm{mg} / \mathrm{kg}$ (5.2:1 and 15.6:1 mixtures) the clomipramine/ nalbuphine mixtures produced greater antinociception than nalbuphine alone. For morphine or methadone at $50^{\circ} \mathrm{C}$, there were significant main effects of doses of morphine $\left(F_{4,12}=\right.$ $108.6 ; p<0.05)$ or methadone $\left(F_{4,12}=52.1 ; p<0.05\right)$, but no significant main effects of clomipramine proportion and no interactions.

For nalbuphine at the $54^{\circ} \mathrm{C}$ thermal intensity, two-way ANOVA indicated significant main effects of nalbuphine dose $\left(F_{4,12}=18.1 ; p<0.05\right)$ and clomipramine proportion $\left(F_{3,9}=\right.$ $9.0 ; p<0.05)$ and a significant interaction $\left(F_{12,35}=2.5 ; p<\right.$ 0.05). Post hoc analysis revealed that at the $1.0 \mathrm{mg} / \mathrm{kg}$ dose of nalbuphine the 15.6:1 clomipramine/nalbuphine mixture produced significantly greater antinociception than nalbuphine alone, and at the $3.2 \mathrm{mg} / \mathrm{kg}$ dose of nalbuphine all clomipramine/nalbuphine mixtures produced significantly greater antinociception than nalbuphine alone. For morphine at the $54^{\circ} \mathrm{C}$ thermal intensity there were significant main effects of morphine dose $\left(F_{4,12}=42.9 ; p<0.05\right)$ and clomipramine proportion $\left(F_{3,9}=5.7 ; p<0.05\right)$ and a significant interaction $\left(F_{12,36}=3.2 ; p<0.05\right)$. Post hoc analysis revealed that at the $3.2 \mathrm{mg} / \mathrm{kg}$ dose of morphine the $0.53: 1$ and $4.8: 1$
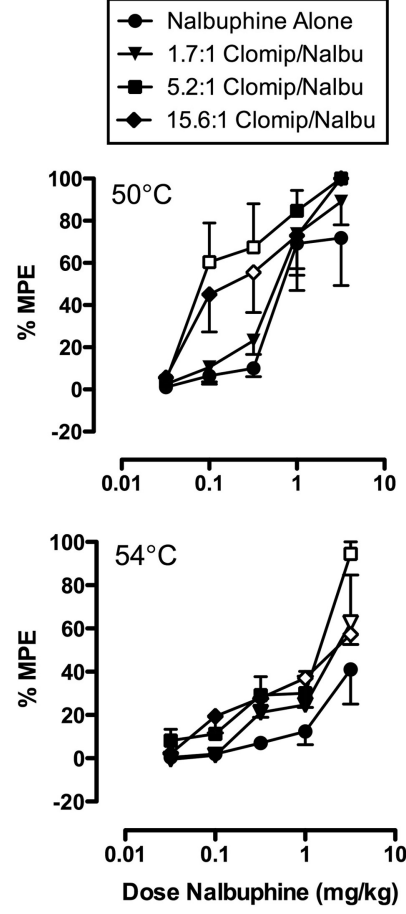
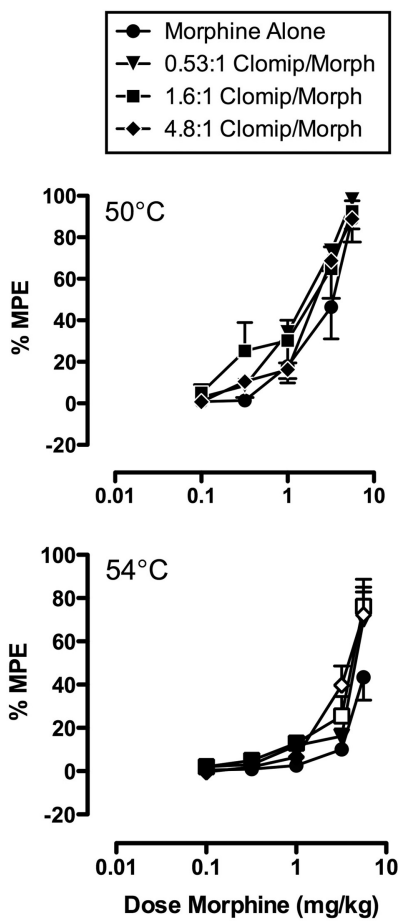
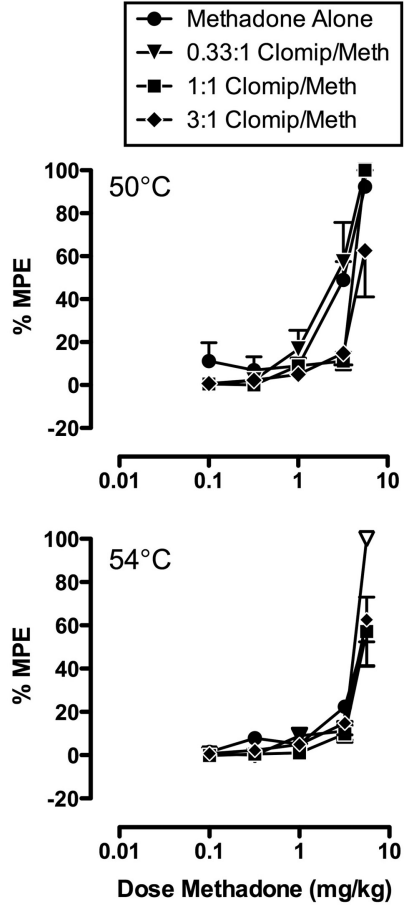

Fig. 2. Effects of nalbuphine (Nalbu; left), morphine (Morph; center), and methadone (Meth; right) alone or in combination with different proportions of clomipramine (Clomip) in the assay of thermal nociception at 50 (top) and $54^{\circ} \mathrm{C}$ (bottom). Abscissae: dose of mu agonist alone or in the mixture in $\mathrm{mg} / \mathrm{kg}$ (log scale). The corresponding dose of clomipramine depended on the proportion of clomipramine in the mixture. Ordinates: \%MPE. Each point shows mean \pm S.E.M. for four monkeys. Open symbols represent significantly $(p<0.05)$ different from mu agonist alone within a given $\mathrm{mu}$ agonist dose. Note that one monkey was tested with a high dose of $10 \mathrm{mg} / \mathrm{kg}$ nalbuphine alone to achieve $>50 \% \mathrm{MPE}$ at $50^{\circ} \mathrm{C}$, but because this was the only monkey tested at this dose, data from this test are excluded. 
clomipramine/morphine mixtures produced significantly greater antinociception than morphine alone, and at the 5.6 $\mathrm{mg} / \mathrm{kg}$ dose of morphine all clomipramine/morphine mixtures produced significantly greater antinociception than morphine alone. For methadone at $54^{\circ} \mathrm{C}$, there was a significant main effect of methadone dose $\left(F_{4,12}=27.6 ; p<0.05\right)$, no significant main effect of clomipramine proportion, and a significant interaction $\left(F_{12,36}=4.2 ; p<0.05\right)$. Post hoc analysis revealed that the $0.33: 1$ clomipramine/methadone mixture produced significantly greater antinociception than methadone alone at the $5.6 \mathrm{mg} / \mathrm{kg}$ dose.

Table 1 shows that clomipramine did not significantly alter $\mathrm{mu}$ agonist $\mathrm{ED}_{50}$ values for the monkeys in which $\mathrm{ED}_{50}$ values could be determined. However, consistent with the ANOVA results described above, clomipramine increased the proportion of monkeys in which $\mathrm{ED}_{50}$ values could be determined for both nalbuphine $\left(50\right.$ and $\left.54^{\circ} \mathrm{C}\right)$ and morphine $\left(54^{\circ} \mathrm{C}\right)$. In contrast, high proportions of clomipramine decreased the proportion of monkeys in which $\mathrm{ED}_{50}$ values could be determined with methadone $\left(54^{\circ} \mathrm{C}\right)$.

Assay of Capsaicin-Induced Thermal Allodynia. Because clomipramine was most effective in enhancing the antinociceptive effects of the low-efficacy mu agonist nalbuphine, a follow-up experiment evaluated effects of clomipramine on the antiallodynic effects of nalbuphine in an assay of capsaicininduced thermal allodynia. In this procedure, the highest thermal stimulus that failed to elicit tail withdrawal before capsaicin treatment was $42^{\circ} \mathrm{C}$ in two monkeys and $46^{\circ} \mathrm{C}$ in one monkey throughout the study. Topical treatment with capsaicin alone produced allodynia as indicated by reduced tail withdrawal latencies at these temperatures to $2.1 \pm 0.1$, $2.3 \pm 0.5,3.8 \pm 1.2$, and $5.6 \pm 1.6 \mathrm{~s}$ at 15, 30, 45, and $60 \mathrm{~min}$ after capsaicin treatment, respectively.

Figure 3 shows the antiallodynic effects of nalbuphine administered alone or in combination with varying proportions of clomipramine, and $\mathrm{ED}_{50}$ values are shown in Table 1. Nalbuphine alone produced dose-dependent antiallodynia,
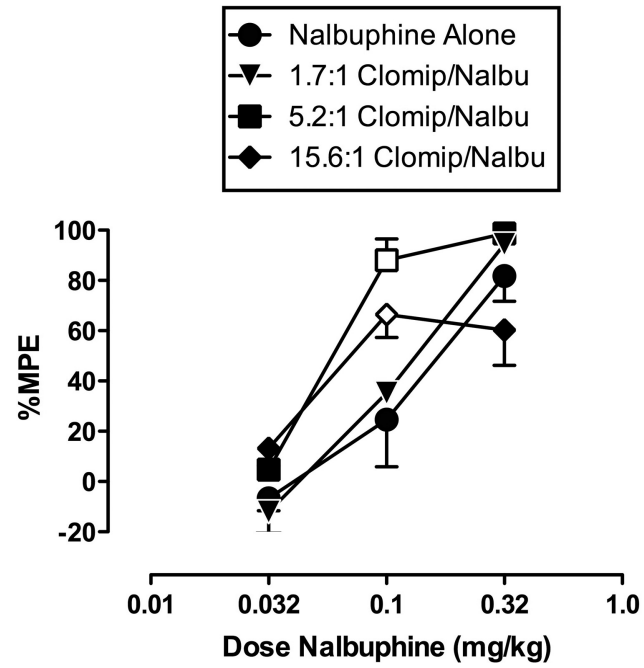

Fig. 3. Effects of nalbuphine (Nalbu) alone or in combination with different proportions of clomipramine (Clomip) in the assay of capsaicininduced thermal allodynia. Abscissa: dose of nalbuphine alone or in the mixture in $\mathrm{mg} / \mathrm{kg}$ (log scale). The corresponding dose of clomipramine depended on the proportion of clomipramine in the mixture. Ordinate: $\%$ MPE. Each point shows mean \pm S.E.M. for three monkeys. Open symbols represent significantly $(p<0.05)$ different from mu agonist alone within a given $\mathrm{mu}$ agonist dose.
TABLE 2

Effects of clomipramine on the relative potency of nalbuphine, morphine, and methadone to produce rate suppression vs. thermal nociception

Experimentally determined dose ratios were calculated as the potency $\left(\mathrm{ED}_{50}\right)$ in the assay of $\mathrm{SCR} /$ potency $\left(\mathrm{ED}_{50}\right)$ in the assay of thermal nociception at stimulus intensities of 50 or $54^{\circ} \mathrm{C}$ or in the assay of capsaicin-induced thermal allodynia.

\begin{tabular}{llcc}
\hline \multicolumn{1}{c}{ Treatment/Condition } & SCR/50 ${ }^{\circ} \mathrm{C}$ & SCR/54 ${ }^{\circ} \mathrm{C}$ & $\begin{array}{c}\text { SCR/Thermal } \\
\text { Allodynia }\end{array}$ \\
\hline Nalbuphine alone & 0.26 & Not calculable & 1.44 \\
1.7:1 Clomip/nalbuphine & $0.15^{*}$ & Not calculable & 0.77 \\
5.2:1 Clomip/nalbuphine & 0.63 & $0.12^{*}$ & 1.67 \\
15.6:1 Clomip/nalbuphine & 0.39 & $0.07^{*}$ & 1.00 \\
Morphine alone & 0.30 & Not calculable & \\
0.53:1 Clomip/morphine & 0.51 & Not calculable & \\
1.6:1 Clomip/morphine & 0.41 & $0.16^{*}$ & \\
4.8:1 Clomip/morphine & $0.27^{*}$ & $0.16^{*}$ & \\
Methadone alone & 0.41 & 0.29 & \\
0.33:1 Clomip/methadone & 0.44 & $0.20^{*}$ & \\
1:1 Clomip/methadone & $0.30^{*}$ & Not calculable & \\
3:1 Clomip/methadone & $0.15^{*}$ & Not calculable & \\
\hline
\end{tabular}

* Indicates that $95 \%$ confidence limits do not overlap between the assay of schedule controlled responding and the assay of thermal nociception at that thermal intensity.

whereas clomipramine alone was completely ineffective (maximum \%MPE of $-8.6 \pm 6.2 \%$ at doses of $1.0-10 \mathrm{mg} / \mathrm{kg}$; data not shown). However, clomipramine enhanced the antiallodynic effects of nalbuphine. Repeated-measures two-way ANOVA demonstrated a significant main effect of nalbuphine dose $\left(F_{2,4}=124.2 ; p<0.05\right)$, no significant main effect of clomipramine proportion, and a significant clomipramine proportion and nalbuphine dose interaction $\left(F_{6,12}=8.4 ; p<\right.$ 0.05). Post hoc analysis revealed that at the $0.1 \mathrm{mg} / \mathrm{kg}$ dose of nalbuphine the 5.2:1 and 15.6:1 clomipramine/nalbuphine mixtures produced significantly greater antiallodynia than nalbuphine alone. Table 1 shows that the 5.2:1 clomipramine/nalbuphine mixture also significantly decreased the $\mathrm{ED}_{50}$ value for nalbuphine.

Dose Ratio Analysis. Table 2 shows the effects of clomipramine on the relative potency of nalbuphine, morphine, and methadone to produce rate suppression versus thermal antinociception. Dose ratios for each mu agonist alone or in combination with varying proportions of clomipramine were calculated as the $\mathrm{ED}_{50}$ in the assay of schedule-controlled responding/ $/ \mathrm{ED}_{50}$ in the assay of thermal nociception at each stimulus intensity. Dose ratios could not be calculated for clomipramine alone at either thermal intensity because of a lack of significant activity in the assay of thermal nociception in all subjects. A dose ratio also could not be calculated for nalbuphine and morphine alone at $54^{\circ} \mathrm{C}$. Clomipramine increased dose ratios relative to nalbuphine alone at both 50 and $54^{\circ} \mathrm{C}$, indicating that clomipramine/nalbuphine mixtures produced antinociception with less rate suppression than nalbuphine alone. Some clomipramine proportions also increased dose ratios for morphine. However, clomipramine produced only a proportion-dependent decrease in the dose ratios for methadone. In the assay of capsaicin-induced thermal allodynia, clomipramine in combination with nalbuphine in the 5.2:1 mixture also increased the dose ratio compared with nalbuphine alone.

Time Course of Clomipramine, Nalbuphine, Morphine, and Methadone in the Assay of Thermal Nociception. Figure 4 shows the time course of clomipramine (10 $\mathrm{mg} / \mathrm{kg})$, nalbuphine $(1.0 \mathrm{mg} / \mathrm{kg})$, morphine $(3.2 \mathrm{mg} / \mathrm{kg})$, and methadone $(3.2 \mathrm{mg} / \mathrm{kg})$ in the assay of thermal nociception at 


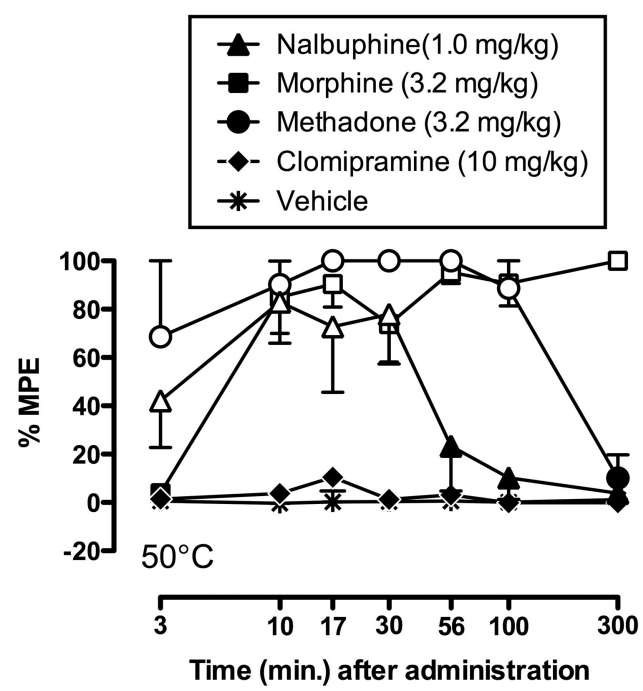

Fig. 4. Time course of antinociceptive effects from the low-efficacy mu agonist nalbuphine, the moderate-efficacy mu agonist morphine, the high-efficacy mu agonist methadone, the serotonin uptake inhibitor clomipramine, and saline administration in different groups of rhesus monkeys. Abscissa: time (min) after administration. Ordinate: \%MPE at the $50^{\circ} \mathrm{C}$ thermal intensity. Each point represents mean \pm S.E.M. of three rhesus monkeys. Two-way repeated-measures analysis of variance revealed a significant main effect of time $\left(F_{6,12}=12.8 ; p<0.05\right)$, drug $\left(F_{4,8}=39.1 ; p<0.05\right)$, and a significant time $\times$ drug interaction $\left(F_{24,48}=\right.$ $9.2 ; p<0.05$ ). Post hoc analysis using the Bonferroni method for multiple planned comparisons demonstrated that nalbuphine and methadone were significantly different $(p<0.05)$ from vehicle at $3 \mathrm{~min}$, and all $\mathrm{mu}$ agonists were significantly different from vehicle at 10 to $30 \mathrm{~min}$. Nalbuphine's effects returned to vehicle levels at $56 \mathrm{~min}$ and methadone levels at $300 \mathrm{~min}$. Morphine's effects were still significant at $300 \mathrm{~min}$. Open symbols represent significantly $(p<0.05)$ different vehicle within a given time point.

the $50^{\circ} \mathrm{C}$ thermal stimulus. All mu agonists produced a significant antinociceptive effect relative to saline treatment. Clomipramine did not produce a significant antinociceptive effect at any time point. Using duration of significant differences from saline treatment as a criterion, durations of action were nalbuphine $<$ methadone $<$ morphine.

\section{Discussion}

This study assessed interactions between the serotonin uptake inhibitor clomipramine and the low-efficacy mu agonist nalbuphine and the moderate-efficacy mu agonist morphine and the high-efficacy mu agonist methadone in assays of schedule-controlled responding, thermal nociception, and capsaicin-induced thermal allodynia. The main findings support the hypothesis that serotonin uptake inhibitors can selectively enhance analgesia-related effects of low- to moderate-efficacy $\mathrm{mu}$ agonists. Mixtures of serotonin uptake inhibitors and low- to moderate-efficacy mu agonists may warrant further consideration and development as candidate analgesics.

Effects of Clomipramine and Mu Agonists Alone. In the present study, the mu agonists nalbuphine, morphine, and methadone all produced dose-dependent decreases in rates of schedule-controlled responding and increases in thermal antinociception consistent with previously published studies (Dykstra and Woods, 1986; Gerak et al., 1994; Gatch et al., 1995, 1998; Stevenson et al., 2003). This is the first study to describe the antiallodynic effects of nalbuphine in nonhuman primates, although nalbuphine was shown to be effective in some rat models of inflammatory pain (Lomas et al., 2007; Ortiz et al., 2007; Ortiz and Castañeda-Hernández, 2008). Clomipramine produced little or no effect up to the highest dose tested in all three assays, which agrees with previous studies in finding that clomipramine and other serotonin uptake inhibitors produce little effect on rates of schedule-controlled responding or thermal nociception in nonhuman primates (Kleven and Woolverton, 1993; Spealman, 1993; Gatch et al., 1998) or pain-related behaviors in rodent models of inflammatory pain (Pedersen et al., 2005).

Antinociceptive Interactions between Clomipramine and Mu Agonists. Some proportions of clomipramine enhanced the antinociceptive effects of nalbuphine or morphine in the thermal nociception assay. These results are consistent with previous studies demonstrating clomipramine-induced enhancement of the antinociceptive effects of nalbuphine (Gatch et al., 1998) and morphine (Kellstein et al., 1984, 1988; Rosland et al., 1988; Ventafridda et al., 1990; Gatch et al., 1998). Furthermore, the relative inability of clomipramine to enhance antinociception produced by the high-efficacy mu agonist methadone agrees with our previous finding that clomipramine did not enhance the antinociceptive effects of the other high-efficacy mu agonist fentanyl (Gatch et al., 1998). Taken together, these results suggest that efficacy of the mu agonist at mu opioid receptors is one important determinant of antinociceptive interactions between serotonin uptake inhibitors and mu agonists. More specifically, serotonin uptake inhibition seems to be especially effective in enhancing the antinociceptive effects of relatively low-efficacy mu-opioid agonists.

A second important determinant of interactions between serotonin uptake inhibitors and mu agonists may be the proportion of the serotonin uptake inhibitor in the mixture, and in the present study maximal enhancement of mu agonist antinociception was observed with low to intermediate clomipramine proportions. The highest proportion of clomipramine failed to produce further enhancement, and in the case of methadone, higher proportions of clomipramine actually attenuated methadone antinociception in some monkeys. These findings suggest a potential biphasic effect of clomipramine on mu agonist antinociception. The mechanisms that might limit or reverse clomipramine effects on mu agonist antinociception remain to be determined. One possibility is that serotonin uptake inhibitors increase serotonin levels at terminals of descending serotonergic neurons in the spinal dorsal horn (Sorkin et al., 1991; Suzuki et al., 2004; Bannister et al., 2009), where low serotonin levels may selectively promote antinociceptive effects, and higher serotonin levels may also engage opposing, pronociceptive systems (Hylden and Wilcox, 1983; Oyama et al., 1996; Suzuki et al., 2002; Rahman et al., 2004). Other studies have also reported evidence for biphasic or opposing antinociceptive and pronociceptive effects of serotonin in the spinal cord; however, in contrast to the implications of the present study, some of these data have been interpreted to suggest that pronociceptive effects predominate at lower serotonin levels and antinociception requires higher serotonin levels (Mason and Gao, 1998; Mason, 2001). Further research will be required to reconcile this apparent discrepancy.

Clomipramine was least effective in enhancing antinociceptive effects of methadone, and as noted above, this is consistent with a role for mu agonist efficacy as a determi- 
nant of clomipramine-mu agonist interactions. However, other factors may also contribute. For example, (-)-methadone inhibited synaptosomal serotonin uptake with a $K_{\mathrm{i}}$ of $14.1 \mathrm{nM}$, whereas (-)-morphine was inactive (Codd et al., 1995). Nalbuphine was not examined. Insofar as methadone's potency to block serotonin uptake is similar to its affinity for mu opioid receptors [e.g., $5.6 \pm 0.4 \mathrm{nM}$ at human mu receptors (Raynor et al., 1995)], methadone may already function as a mixed mu agonist/serotonin uptake inhibitor, and the addition of clomipramine may engage pronociceptive serotonergic systems more readily with methadone than with other opioids that lack activity at serotonin transporters.

The experimental design of the present study used fixedproportion drug mixtures rather than fixed-dose pretreatments to evaluate clomipramine-mu agonist interactions. From a methodological perspective, this approach permits direct evaluation of drug combinations similar to the many fixed-proportion mixtures that are used clinically to treat pain (e.g., mu agonist-acetaminophen preparations). Moreover, the use of fixed-proportion mixtures facilitates the application of dose-addition analysis to categorize and quantify interactions as synergistic, additive, or subadditive (Tallarida, 2000). We have used this analysis previously to study interactions between mu agonists and other drugs (Stevenson et al., 2003; Negus et al., 2008). In the present study, dose-addition analysis turned out to be unnecessary, because clomipramine was inactive in all procedures, and when one drug in a mixture is inactive, dose-addition analysis reduces to a simple analysis of the degree to which the inactive drugs alters effects of the active drug. Thus, clomipramine-mu agonist interactions were synergistic, additive or subadditive to the degree that clomipramine significantly enhanced, failed to alter, or attenuated effects of the mu agonist.

Selectivity of Clomipramine-Mu Agonist Interactions. In contrast to clomipramine's enhancement of the antinociceptive effects of nalbuphine $>$ morphine $>$ methadone, clomipramine had little or no effect on the rate-decreasing effects of any of the mu agonists in an assay of foodmaintained, schedule-controlled responding. These findings suggest at least two conclusions. First, clomipramine-induced enhancement of mu agonist antinociception did not result from a generalized depression of all behavior. Second, at least some degree of behavioral selectivity in the ability of clomipramine to enhance antinociceptive effects versus other effects of mu agonists is expected. This behavioral selectivity of clomipramine to enhance antinociceptive versus rate-decreasing effects of mu agonists was reflected in clomipramine-induced changes in mu agonist dose ratios to produce antinociception versus rate-decreasing effects. Thus, some fixed-proportion mixtures of clomipramine and nalbuphine or morphine produced dose ratios that were greater than the mu agonist alone. In contrast, clomipramine produced only proportion-dependent decreases in dose ratios for methadone. Further research will be required to evaluate the degree to which clomipramine or other serotonin uptake inhibitors might alter other, potentially problematic effects of mu agonists such as respiratory depression, constipation, or abuse-related effects.

Antiallodynic Interactions between Clomipramine and Nalbuphine. The generality of analgesia-related interactions between clomipramine and nalbuphine was tested in the present study in a model of inflammatory pain. Nalbu- phine was more potent in the assay of capsaicin-induced thermal allodynia than in the assay of thermal nociception, which is consistent with previous results with morphine in this procedure (Do Carmo et al., 2008). As in the assay of thermal nociception, clomipramine enhanced the antiallodynic effects of nalbuphine, and peak levels of enhancement were achieved with the intermediate proportion of 5.2:1 clomipramine/nalbuphine. Thus, clomipramine interactions with analgesia-related effects of nalbuphine were similar in both procedures. These results agree with the finding that the serotonin uptake inhibitor fluoxetine enhanced effects of morphine in the formalin test in rats (Nayebi et al., 2001).

Comparison with Interactions between Mu Agonists and Other Drugs. Results of the present study can be considered in the context of other studies conducted under identical conditions that have examined fixed-proportion drug mixtures of other drug classes in combinations with mu agonists. For example, like clomipramine, delta-opioid receptor agonists also produced a selective enhancement in the antinociceptive effects of $\mathrm{mu}$ agonists in rhesus monkeys (Stevenson et al., 2003; Negus et al., 2009). However, in contrast to the effects observed with clomipramine, delta agonist enhancement of mu agonist antinociception did not depend on the efficacy of the mu agonist. For example, the delta agonist SNC80 [(+)-4-[( $\alpha R)-\alpha-((2 S, 5 R)-4$-allyl-2,5dimethyl-1-piperazinyl)-3-methoxybenzyl]- $N, N$-diethylbenzamide] produced a robust enhancement of the antinociceptive effects of methadone. Previous studies have also examined interactions between the high-efficacy mu agonist fentanyl and either the kappa-opioid agonist U-69593 [ $N$-methyl-2-phenyl$N$-[(5R,7S,8S)-7-(pyrrolidin-1-yl)-1-oxaspiro[4.5]dec-8yl]acetamide] or the noncompetitive $N$-methyl-D-aspartate glutamate receptor antagonist ketamine. U-69593 produced only additive antinociceptive interactions in combination with fentanyl, but it tended to attenuate the rate-decreasing effects of fentanyl in the assay of schedule-controlled responding, and as a result, some U-69593/fentanyl proportions displayed higher dose ratios for antinociception versus rate suppression than fentanyl alone (Negus et al., 2008). Conversely, ketamine produced greater enhancement of the rate decreasing versus antinociceptive effects of fentanyl, and as a result, ketamine produced only a proportiondependent decrease in dose ratios for antinociception versus rate suppression (Banks et al., 2010). Taken together, these studies illustrate the potential for a variety of different outcomes when mu agonists are combined with other drugs.

Drug Time Course as a Factor in Drug Interactions. Drug interactions can be influenced by the time courses of drugs in a mixture, and differences in mu agonist/clomipramine interactions may have been influenced by the time courses rather than the efficacies of the mu agonists. However, the relative degrees of clomipramine enhancement (nalbuphine $>$ morphine $>$ methadone) did not correlate with either rate of onset (methadone $\geq$ nalbuphine $>$ morphine) or duration of action (morphine $>$ methadone $>$ nalbuphine) of approximately equi-analgesic mu agonist doses. Moreover, although clomipramine clearly enhanced antinociception induced by the rapid-onset, short-acting mu agonist nalbuphine, it did not enhance antinociceptive effects of similarly rapid-onset, short-acting mu agonist fentanyl, which has relatively high efficacy at mu receptors (Gatch et al., 1998). Taken together, these results suggest that time 
course is less important than mu agonist efficacy as a determinant of interactions between mu agonists and serotonin uptake inhibitors.

\section{Acknowledgments}

We thank Ember Morrissey and Crystal Reyns for technical assistance.

\section{References}

Ansuategui M, Naharro L, and Feria M (1989) Noradrenergic and opioidergic influences on the antinociceptive effect of clomipramine in the formalin test in rats. Psychopharmacology 98:93-96.

Banks ML, Folk JE, Rice KC, and Negus SS (2010) Selective enhancement of fentanyl-induced antinociception by the delta agonist SNC162 but not by ketamine in rhesus monkeys: further evidence supportive of delta agonists as candidate adjuncts to mu opioid analgesics. Pharmacol Biochem Behav doi:10.1016/ j.pbb.2010.07.019.

Bannister K, Bee LA, and Dickenson AH (2009) Preclinical and early clinical investigations related to monoaminergic pain modulation. Neurotherapeutics 6:703712 .

Basbaum AI and Fields HL (1984) Endogenous pain control systems: brainstem spinal pathways and endorphin circuitry. Annu Rev Neurosci 7:309-338.

Butelman ER, Harris TJ, and Kreek MJ (2004) Antiallodynic effects of loperamide and fentanyl against topical capsaicin-induced allodynia in unanesthetized primates. J Pharmacol Exp Ther 311:155-163.

Codd EE, Shank RP, Schupsky JJ, and Raffa RB (1995) Serotonin and norepinephrine uptake inhibiting activity of centrally acting analgesics: structural determinants and role in antinociception. J Pharmacol Exp Ther 274:1263-1270.

Dietis N, Guerrini R, Calo G, Salvadori S, Rowbotham DJ, and Lambert DG (2009) Simultaneous targeting of multiple opioid receptors: a strategy to improve sideeffect profile. $\mathrm{Br}$ J Anaesth 103:38-49.

Do Carmo GP, Polt R, Bilsky EJ, Rice KC, and Negus SS (2008) Behavioral phar macology of the mu/delta opioid glycopeptide MMP2200 in rhesus monkeys. $J$ Pharmacol Exp Ther 326:939-948.

Dykstra LA and Woods JH (1986) A tail withdrawal procedure for assessing analgesic activity in rhesus monkeys. J Pharmacol Methods 15:263-269.

Fields HL, Basbaum AI, and Heinricher MM ()(2006) Central nervous system mechanisms of pain modulation, in Textbook of Pain (McMahon SB, Koltzenburg M eds) pp 125-142, Elsevier Churchill Livingstone, London.

Gatch MB, Negus SS, Butelman ER, and Mello NK (1995) Antinociceptive effects of cocaine/opioid combinations in rhesus monkeys. J Pharmacol Exp Ther 275:1346 1354.

Gatch MB, Negus SS, and Mello NK (1998) Antinociceptive effects of monoamine reuptake inhibitors administered alone or in combination with mu opioid agonists in rhesus monkeys. Psychopharmacology 135:99-106.

Gerak LR, Butelman ER, Woods JH, and France CP (1994) Antinociceptive and respiratory effects of nalbuphine in rhesus monkeys. $J$ Pharmacol Exp Ther 271:993-999

Hylden JL and Wilcox GL (1983) Intrathecal serotonin in mice: analgesia and inhibition of a spinal action of substance P. Life Sci 33:789-795.

Kellstein DE, Malseed RT, and Goldstein FJ (1984) Contrasting effects of acute vs. chronic tricyclic antidepressant treatment on central morphine analgesia. Pain 20:323-334.

Kellstein DE, Malseed RT, Ossipov MH, and Goldstein FJ (1988) Effect of chronic treatment with tricyclic antidepressants upon antinociception induced by intrathecal injection of morphine and monoamines. Neuropharmacology 27:1-14

Kleven MS and Woolverton WL (1993) Effects of three monoamine uptake inhibitors on behavior maintained by cocaine or food presentation in rhesus monkeys. Drug Alcohol Depend 31:149-158.

Lomas LM, Barrett AC, Terner JM, Lysle DT, and Picker MJ (2007) Sex differences in the potency of $\kappa$ opioids and mixed-action opioids administered systemically and at the site of inflammation against capsaicin-induced hyperalgesia in rats. Psychopharmacology 191:273-285.

Mason P (2001) Contributions of the medullary raphe and ventromedial reticular region to pain modulation and other homeostatic functions. Annu Rev Neurosci 24:737-777.

Mason P and Gao K (1998) Raphe magnus serotonergic neurons tonically modulate nociceptive transmission. J Pain 7:143-150.

Nayebi AR, Hassanpour M, and Rezazadeh H (2001) Effect of chronic and acute administration of fluoxetine and its additive effect with morphine on the behavioural response in the formalin test in rats. J Pharm Pharmacol 53:219-225.

Negus SS, Bear AE, Folk JE, and Rice KC (2009) Role of delta opioid efficacy as a determinant of mu/delta opioid interactions in rhesus monkeys. Eur J Pharmacol 602:92-100.

Negus SS, Butelman ER, Al Y, and Woods JH (1993) Prostaglandin E2-induced thermal hyperalgesia and its reversal by morphine in the warm-water tailwithdrawal procedure in rhesus monkeys. J Pharmacol Exp Ther 266:1355-1363.

Negus SS, Schrode K, and Stevenson GW (2008) Micro/kappa opioid interactions in rhesus monkeys: implications for analgesia and abuse liability. Exp Clin Psychopharmacol 16:386-399.

Ortiz MI and Castañeda-Hernández G (2008) Examination of the interaction between peripheral lumiracoxib and opioids on the $1 \%$ formalin test in rats. Eur $J$ Pain 12:233-241.

Ortiz MI, Ponce-Monter H, Fernández-Martínez E, Pérez-Hernández N, Macías A Rangel-Flores E, and Castañeda-Hernández G (2007) Evaluation of the interaction between acemetacin and opioids on the hargreaves model of thermal hyperalgesia. Pharmacol Biochem Behav 88:47-54.

Oyama T, Ueda M, Kuraishi Y, Akaike A, and Satoh M (1996) Dual effect of serotonin on formalin-induced nociception in the rat spinal cord. Neurosci Res 25:129-135.

Pedersen LH, Nielsen AN, and Blackburn-Munro G (2005) Anti-nociception is selectively enhanced by parallel inhibition of multiple subtypes of monoamine transporters in rat models of persistent and neuropathic pain. Psychopharmacology 182:551-561.

Pisani F, Oteri G, Costa C, Di Raimondo G, and Di Perri R (2002) Effects of psychotropic drugs on seizure threshold. Drug Safety 25:91-110.

Rahman W, Suzuki R, Rygh LJ, and Dickenson AH (2004) Descending serotonergic facilitation mediated through rat spinal 5HT3 receptors is unaltered following carrageenan inflammation. Neurosci Lett 361:229-231.

Raynor K, Kong H, Mestek A, Bye LS, Tian M, Liu J, Yu L, and Reisine T (1995 Characterization of the cloned human mu opioid receptor. J Pharmacol Exp Ther 272:423-428.

Rosland JH, Hunskaar S, and Hole K (1988) Modification of the antinociceptive effect of morphine by acute and chronic administration of clomipramine in mice. Pain 33:349-355.

Sierralta F, Pinardi G, Mendez M, and Miranda HF (1995) Interaction of opioids with antidepressant-induced antinociception. Psychopharmacology 122:374-378.

Sorkin LS, Hughes MG, Liu D, Willis WD Jr, and McAdoo DJ (1991) Release and metabolism of 5-hydroxytryptamine in the cat spinal cord examined with microdialysis. J Pharmacol Exp Ther 257:192-199.

Spealman RD (1993) Modification of behavioral effects of cocaine by selective serotonin and dopamine uptake inhibitors in squirrel monkeys. Psychopharmacology (Berl) 112:93-99.

Stevenson GW, Folk JE, Linsenmayer DC, Rice KC, and Negus SS (2003) Opioid interactions in rhesus monkeys: effects of $\delta+\mu$ and $\delta+\kappa$ agonists on schedulecontrolled responding and thermal nociception. J Pharmacol Exp Ther 307:10541064.

Suzuki R, Morcuende S, Webber M, Hunt SP, and Dickenson AH (2002) Superficial NK1-expressing neurons control spinal excitability through activation of descending pathways. Nat Neurosci 5:1319-1326.

Suzuki R, Rygh LJ, and Dickenson AH (2004) Bad news from the brain: descending 5-HT pathways that control spinal pain processing. Trends Pharmacol Sci 25:613617

Tallarida RJ (2000) Drug Synergism and Dose-Effect Data Analysis. Chapman and Hall/CRC, Boca Raton, FL.

Ventafridda V, Bianchi M, Ripamonti C, Sacerdote P, De Conno F, Zecca E, and Panerai AE (1990) Studies on the effects of antidepressant drugs on the antinociceptive action of morphine and on plasma morphine in rat and man. Pain 43:155 162

Address correspondence to: S. Stevens Negus, Department of Pharmacology and Toxicology, Virginia Commonwealth University, 410 North 12 th Street, P.O. Box 980613, Richmond, VA 23298. E-mail: ssnegus@vcu.edu 